\title{
Characteristics of Indoor Lighting Environment Using Daylight with a Light Shelf
}

\author{
Hideaki Kido and Yasuyuki Shiraishi
}

\begin{abstract}
We carried out measurements and lighting simulations of an existing office building in order to clarify the characteristics of indoor lighting environments using daylight with a light shelf. Paired comparison measurements were performed to elucidate the difference between using only a light shelf and using a light shelf with a blind in terms of horizontal illuminance and window luminance. Next, the effect of the light shelf's presence or absence on indoor lighting environments was verified through lighting simulations.

Measurements and simulations revealed that when a light shelf was available, the luminance of the upper part of the window was higher than that of the lower part, suggesting that glare does not result from the lower part of the window. We also found that using a light shelf increased horizontal illuminance by about $10 \%$ over the case of no light shelf. The illuminance distribution of the ceiling indicated that illuminance was high at the window and that reflected diffuse light reached the back of the room, so that it was obvious effect on the horizontal illuminance distribution.
\end{abstract}

Index Terms-Daylight, measurement, lighting environment, light shelf.

\section{INTRODUCTION}

Trends toward increased emphasis on saving energy have extended to architectural design, drawing attention to design techniques that harness natural energy. Effective use of daylight is a comparatively simple form of energy transformation, but daylight is influenced by the weather and is unreliable as a stable indoor lighting source. Also, introducing daylight to indoor spaces can increase cooling load in summer. Therefore, research and detailed analysis of both lighting and thermal environments are necessary for building design [1]. We used measurements and lighting simulations to evaluate the indoor lighting environment of an office building with a light shelf as part of a comprehensive evaluation of indoor environments using daylight.

\section{OVERVIEW OF MEASUREMENTS}

\section{A. Measured Building}

The measured office building was the Technology development and Exchange Center in the Kitakyushu Science and Research Park in Fukuoka, Japan (Fig. 1 and Table I). This building has a light shelf on its south side. Comparison measurements were performed at two southward facing, third floor rooms.

Manuscript received June 19, 2013; revised July 23, 2013.

The authors are with The University of Kitakyushu, Japan (e-mail: t2mbb011@eng.kitakyu-u.ac.jp; shiraishi@kitakyu-u.ac.jp).

\section{B. Measurements Performed}

Measurements were performed in room A, which has only a light shelf (Fig. 2), and in room B, which has both a light shelf and solar shading with a blind (Fig. 3). Table II lists the measurements performed.

Case 1 examines the influence of the light shelf and blind; the blind has upward-facing slats over the upper window and downward-facing slats over the lower window. Case 2 introduces control of the blind over the lower window: the blind is open after 12:00.

The horizontal illuminance and the window luminance distributions were measured in the above setup. Figure 4 shows the measurement points. The air-conditioning system was used to set room temperature at $26^{\circ} \mathrm{C}$, and mechanical ventilation was turned off. Measurements were performed from September 25 to 30, 2010.

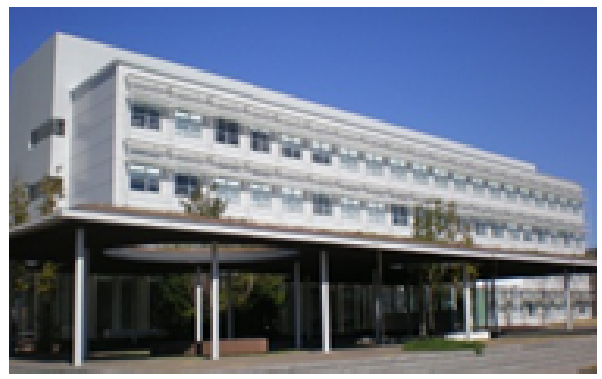

Fig. 1. Appearance

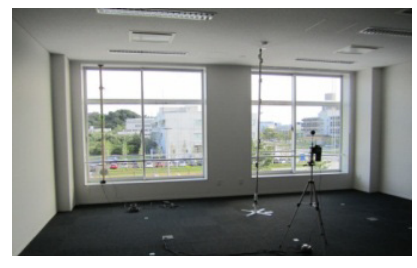

Fig. 2. Room A

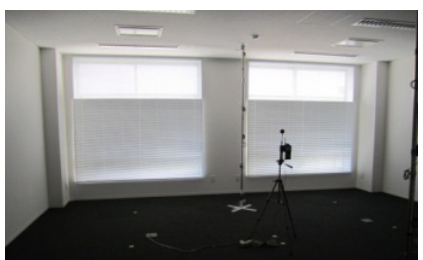

Fig. 3. Room B

\begin{tabular}{c|c}
\multicolumn{2}{c}{ TABLE I: OVERVIEW OF BUILDING } \\
\hline Total floor area & $5607.89 \mathrm{~m}^{2}$ \\
\hline Architecture area & $2594.17 \mathrm{~m}^{2}$ \\
\hline Completion year & 2008 \\
\hline Building construction & Steel structure \\
\hline Floor number & $4 \mathrm{~F}$ \\
\hline
\end{tabular}

TABLE II: THE MEASUREMENTS PERFORMED

\begin{tabular}{|c|c|c|c|c|}
\hline \multirow{2}{*}{ case } & \multicolumn{2}{|c|}{ Theroom A } & \multicolumn{2}{c|}{ Theroom B } \\
\cline { 2 - 5 } & Blind & Artificial lighting & Blind & Artificial lighting \\
\hline $1-1$ & $\times$ & OFF & $\circ$ & OFF \\
\hline $1-2$ & $\times$ & OFF & $\begin{array}{c}0 \\
\text { (control) }\end{array}$ & OFF \\
\hline
\end{tabular}




\section{MEASUREMENT RESULtS}

\section{A. Horizontal Illuminance}

Fig. 5 shows levels of illumination from the window side to the inner side. In room A of case 1, illumination was outstanding by the window, and the illumination changed significantly from the window side to the inner side. In room $\mathrm{B}$, on the other hand, excessive illumination by the window was reduced greatly by the shading effect of the blind, but illumination at the inner side remained below $750 \mathrm{~lx}$ throughout the day. Similarly, in case 2, direct solar radiation entering from under the light shelf was shaded in the morning. Indirect light was provided in the afternoon by moving the blind up and down. As a result, as shown in Fig. 5 the illumination in 10:00 decreased more than 16:00.

\section{B. Window Luminance Distribution}

Fig. 6 shows the average value of luminance at the upper, center, and lower parts of the window. As a general trend, luminance was highest at the upper part, increasing to a peak at 10:00 and then decreasing. Results indicate that shading is important during the morning.

The results for case 1 show that using a blind reduced luminance in the upper and center parts. There was little difference in the lower part. Also, in case 2, opening the blind over the lower window increased the luminance of the center part. However, luminance was sharply reduced until 12:00, the peak hours of the luminance, at which time the blind was closed.

\section{OUtLine OF Lighting Simulation}

Measurement results clarified the indoor lighting environment when using daylight with a light shelf, but it is difficult to grasp the details of indoor lighting environments by measurement results alone. In particular, these measurements do not address seasonal differences or the effect of the light shelf's absence. Thus a detailed verification was performed on an office building by using the DIALux lighting simulation tool.

Fig. 7 and 8 show the office building model used. The reflectance of components and other elements were established by design drawings and field measurements. Tables III show details of the analysis conditions.

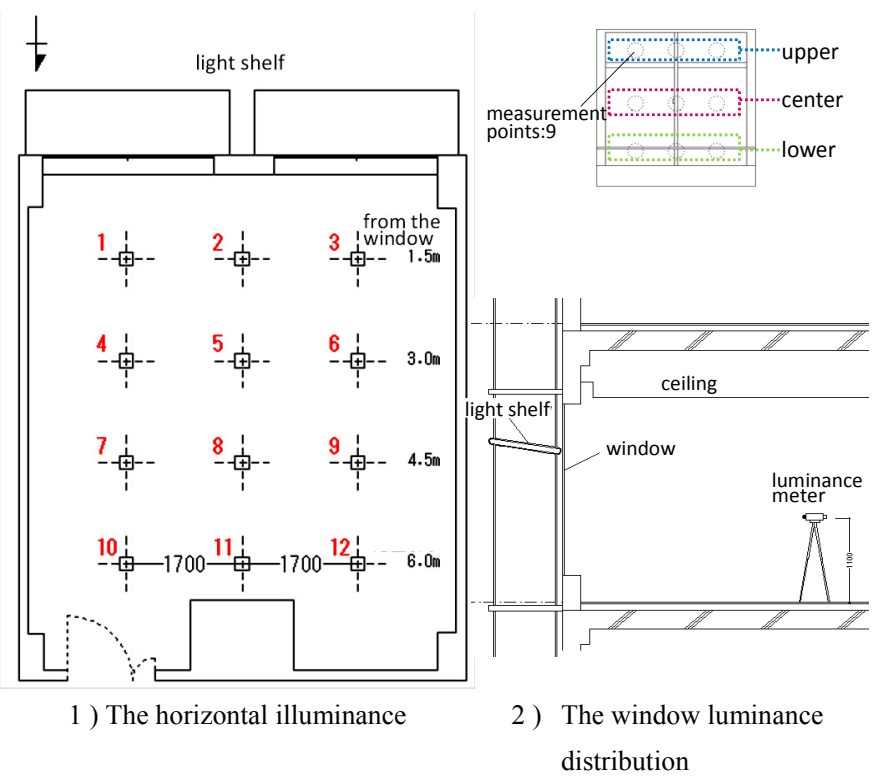

Fig. 4. The measurement points
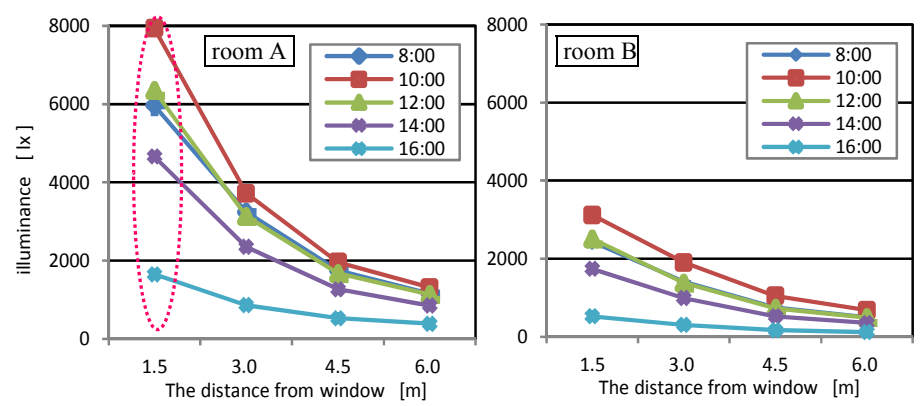

1) case 1
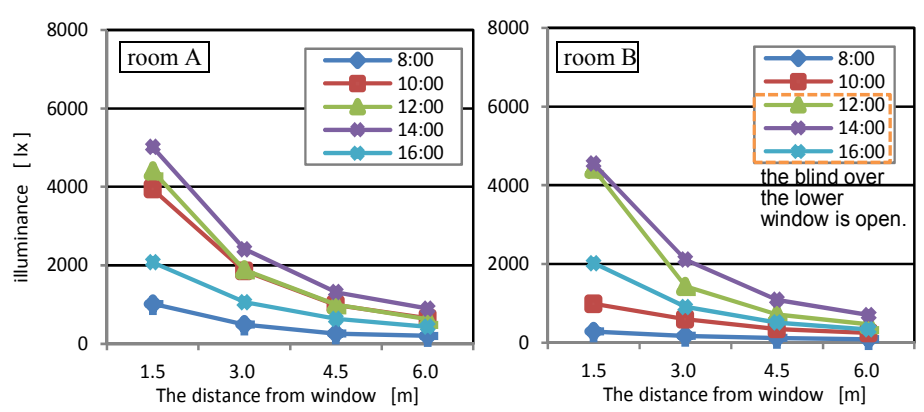

2) case 2
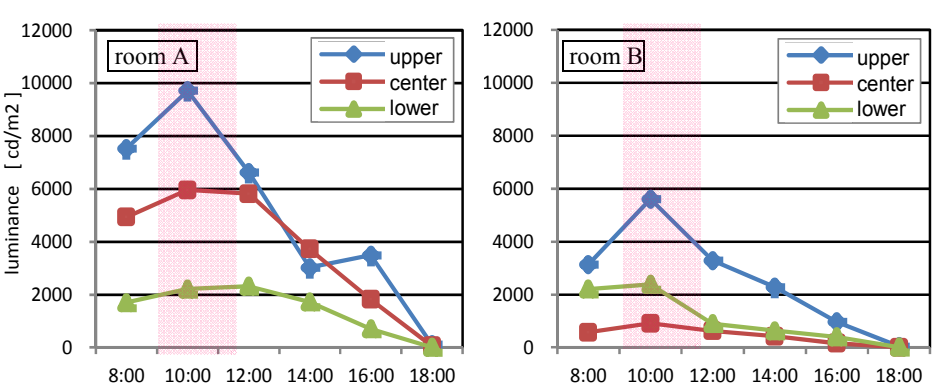

1) case 1
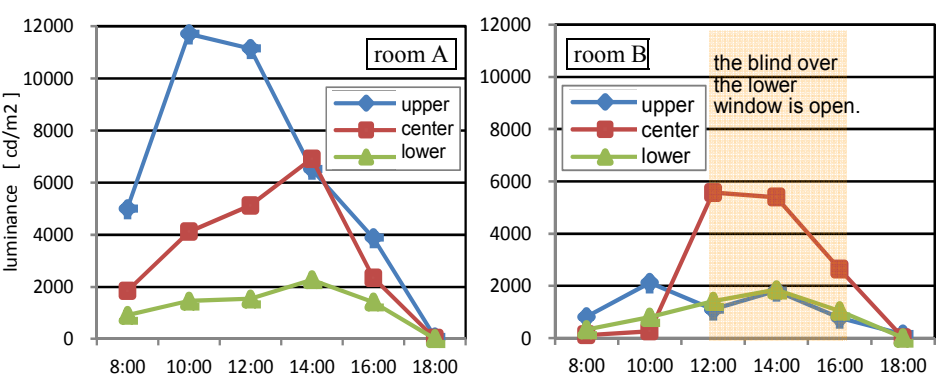

2) case 2

Fig. 5. Levels of horizontal illumination

Fig. 6. Distributions of window luminance 


\section{ANALysis RESUlts}

\section{A. Verification of Prediction Accuracy}

To verify the prediction accuracy of the simulation model, analysis results were compared with the results obtained by measurement. Fig. 9 shows the results of illumination comparisons in case 1. It also shows the root-mean-square error (RMSE) for distance from a window. The results in room A had error with $\mathrm{RMSE}=9875.21 \times$ at $1.5 \mathrm{~m}$ distance. The RMSE decreased with increasing distance from the window side. It is conceivable that, near the window, measurement of direct light induced error. Another possible factor influencing reflection of the detailed window sash and others not duplicated in DIALux is the inability of DIALux to duplicate wall thickness [2]. On the other hand, the simulation results generally corresponded to the measurements in room $\mathrm{B}$.

As mentioned above, some problems remain in regard to the accuracy of lighting environment predictions at the window side, and remain as issues to be addressed in the future. However, because results corresponded in all measurement positions other than the window side, this model should be sufficiently useful as a tool for evaluating indoor lighting environments in the design stage.

\section{B. Assessment of Uncomfortable Glare}

Assessment of uncomfortable glare at the window side was performed by using the predicted glare sensation vote (PGSV) [3].

$$
P G S V=\log _{10} \frac{L_{w}^{3.2} \cdot \omega^{0.64}}{L_{b}{ }^{0.61-0.79 \log _{10} \omega}}-8.2
$$

Here, $L_{w}$ is the window luminance $\left[\mathrm{cd} / \mathrm{m}^{2}\right], L_{b}$ is the background luminance $\left[\mathrm{cd} / \mathrm{m}^{2}\right]$, and $\omega$ is the solid angle of window [sr]. Measured values were used for $L_{w}$, and analysis results were used for $L_{b}$.

Fig. 10 shows the PGSV results in case 1. PGSV values of 0 or more indicate glare, and values of -0.5 is generally taken as ideal (no glare). PGSV was high at the upper part of the window, but the lower part was not glaring. Using the blind reduced PGSV to a degree where slight glare arose in the morning. When a light shelf was available, the glare of the whole window resulted from the upper part of the window.

\section{Effects of the Presence of a Light Shelf}

We used simulations to verify the effect of the presence or absence of a light shelf on indoor lighting environments. As Fig. 11 indicates, introducing a light shelf increased horizontal illuminance $(750 \mathrm{~mm})$ by $10 \%$.

As an example, Fig. 12 shows the illuminance distribution of the ceiling at 14:00; the light shelf increases ceiling illuminance at the window side. Moreover, the illumination change was moderated at the inner side, and reflected diffuse light efficiently reached the back of the room. It is thus obvious that this illuminance distribution is also reflected in the horizontal illuminance.

\section{Illuminance Distribution in Summer And Winter}

Since the measurement was performed only for spring and fall, the lighting environments in summer (August) and winter (January) were evaluated by using the simulation, and compared with moderate seasons.

Fig. 13 shows the illuminance distribution at 14:00. In winter, illumination of more than $7501 \times$ was provided at the inner side using daylight. Indeed, varying seasons had little influence on the illuminance distribution at the inner side.
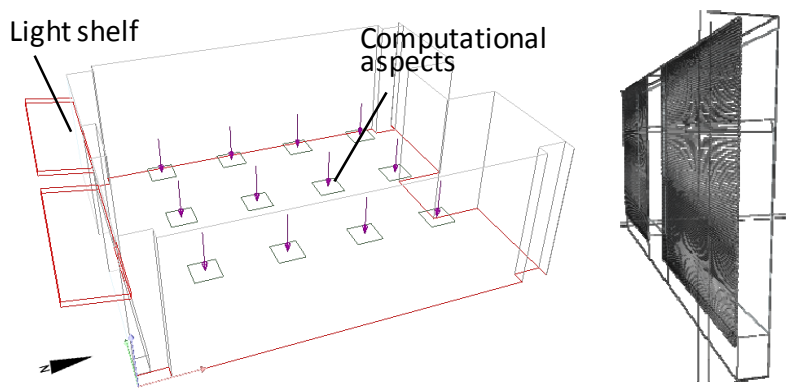

Fig. 7. Room model

Fig. 8. Blind model

TABLE III: ANALYSIS CONDITIONS

\begin{tabular}{|c|c|}
\hline Window & Reflectance $=10 \%$, Transmittance $=90 \%$ \\
\hline Blind [5] & $\begin{array}{l}\text { Upward-facing Slats }=+45^{\circ} \\
\text { Downward-facing Slats }=-45^{\circ} \\
\text { Reflectance }=60 \% \\
\text { Color }=\text { White }\end{array}$ \\
\hline Room & $\begin{array}{l}\text { Celling Reflectance }=70 \% \\
\text { Wall Reflectance }=60 \% \\
\text { Floor Reflectance }=20 \% \\
\text { Light Shelf Reflectance }=90 \%\end{array}$ \\
\hline Site & Kitakyushu, Japan (N 3353, E13052) \\
\hline Sky & Clear Sky(CIE) [6],[7] \\
\hline Ground & Reflectance $=30 \%$ \\
\hline
\end{tabular}

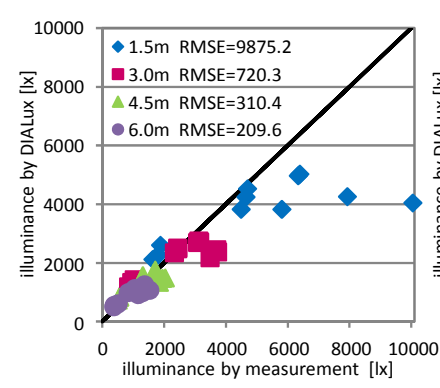

1) Room $A$

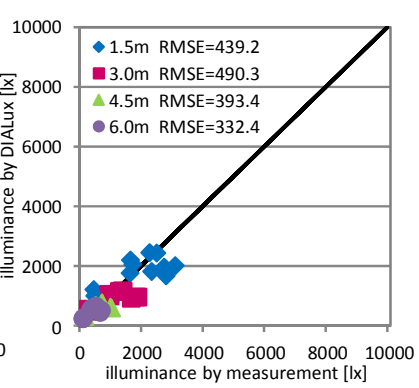

2) Room B
Fig. 9. The results of illumination comparisons (case 1)

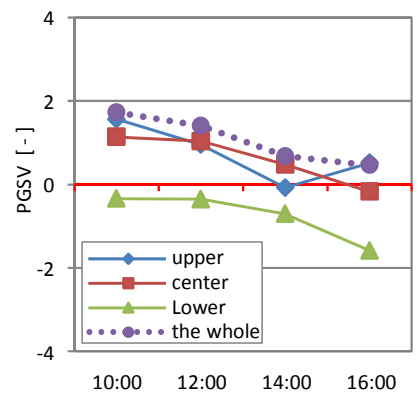

1) Room $A$

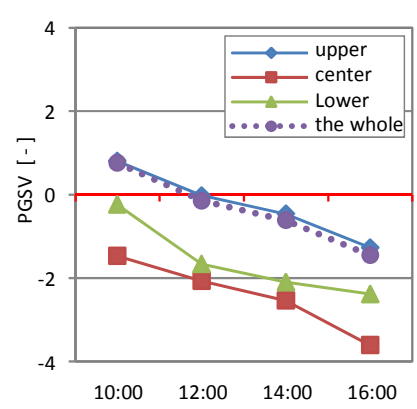

2) Room B
Fig. 10. The PGSV results (case 1) 


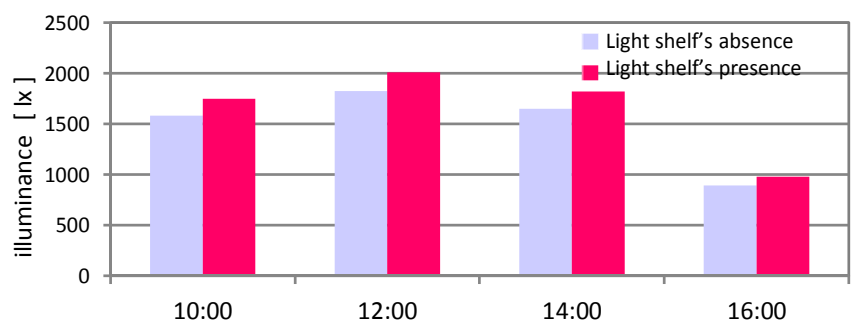

Fig. 11. Effects of the presence of a light shelf

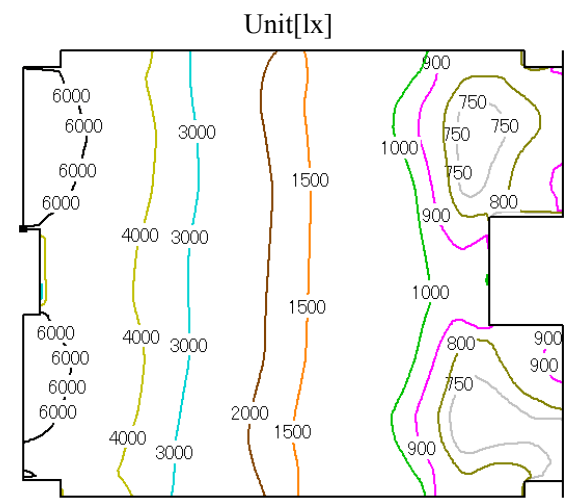

1) Light shelf's absence

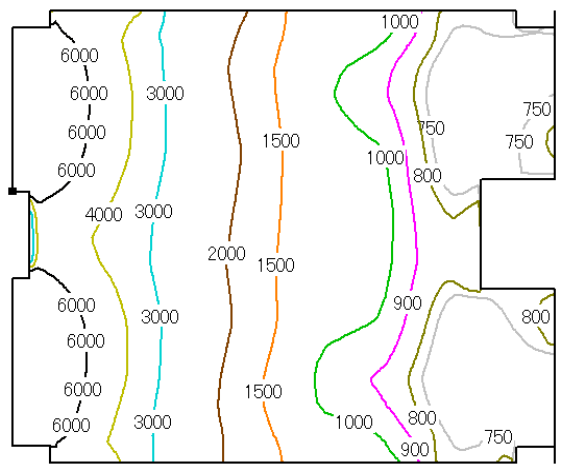

2) Light

Fig. 12. The illuminance distribution of the ceiling

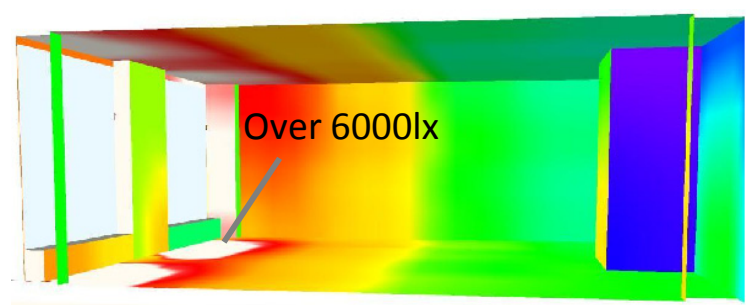

1) Summer

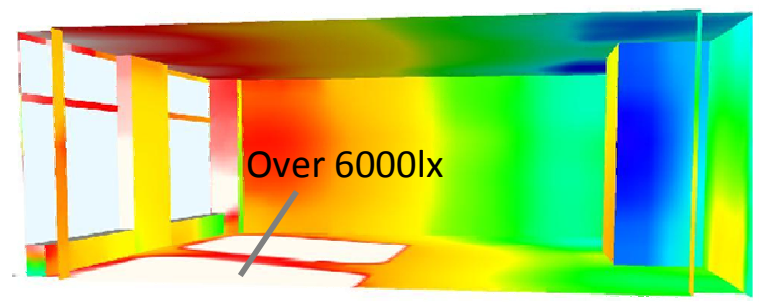

2) Spring and Fall

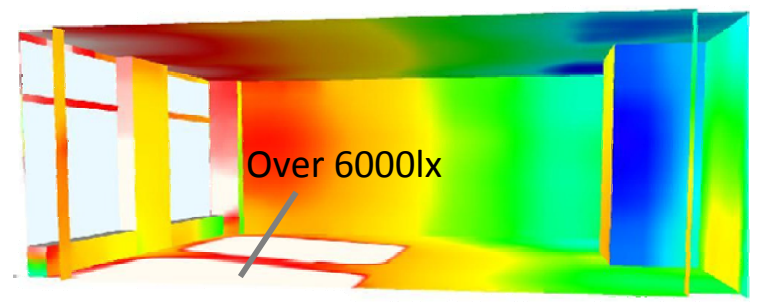

3) Winter

Fig. 13. The illuminance distribution
The illuminance distributions by the window, on the other hand, differed greatly by season. Since the solar altitude is higher in summer, the distribution in summer was more skewed toward the window side than in spring and fall. However, excessive illumination was produced that reached the center of the room in winter, likely because direct solar radiation entering from under the light shelf was higher in winter which solar altitudes are lower. Although indoor illumination rose overall in winter, the area of distribution of excessive illumination also expanded. The lighting environment in summer was therefore more consistent than that in other seasons.

\section{Conclusions}

The characteristics of indoor lighting environments using daylight with a light shelf were elucidated through measurements and lighting simulations. In future studies, we plan to investigate indoor thermal environments, because comprehensive evaluations of such are needed to provide a deeper understanding of indoor environments that utilize daylight.

We used simulations to verify the effect of the presence or absence of a light shelf on indoor lighting environments. The light shelf increases ceiling illuminance at the window side. Moreover, the illumination change was moderated at the inner side, and reflected diffuse light efficiently reached the back of the room at 14:00. The lighting environments in summer (August) and winter (January) were evaluated by using the simulation, and compared with moderate seasons. Indoor illumination rose overall in winter, the area of distribution of excessive illumination also expanded. The lighting environment in summer was therefore more consistent than that in other seasons.

\section{REFERENCES}

[1] T. Kikuchi, M. Higuchi, N. Igawa, "Simulation study of impact of energy saving effect and indoor environment by daylighting," Architectural Institute of Japan, pp.133-139, February 2009.

[2] DIALux official website. [Online]. Available: http://dialux.com/

[3] M. Tokura, T. Iwata, and M. Syukuya, "Experimental study on discomfort glare caused by windows - Part3: Development of a method for evaluating discomfort glare from a large light source," $J$ Archit. Plann. Environ. Eng., AIJ, 1996.

[4] Daylight illumination design guide, Architectural Institute of Japan, 2007.

[5] T. Kikuchi and N. Igawa, "Evaluation of transmission characteristics of shading device with sky radiance distribution model," Architectural Institute of Japan, pp.17-24, January 2009

[6] N. Yoshizawa, K. Kobayashi, M. Inanuma and H. Takeda, "Typical annual weather data (TWD9302/L) in Tokyo area and its application to the daylighting simulation," Architectural Institute of Japan, pp.23-29, December 2005

[7] H. Hosobuchi, H.Yoshida and Y. Uetani, "The examination of applying the CIE standard general sky to sky radiance distribution and sky type integration," Architectural Institute of Japan, pp. 29-36, September 2004.

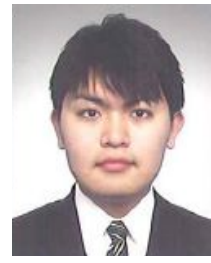

Hideaki Kido is a graduate student of The University of Kitakyushu Japan. 